https://doi.org/10.48009/1_iis_2008_16-20

\title{
DO SELECTED VARIABLES SIGNIFICANTLY PREDICT AND EXPLAIN STUDENT HANDS-ON PERFORMANCE AND THEORY EXAM SCORES IN AN INTRODUCTORY INFORMATION SYSTEMS COURSE?
}

\author{
Dr. Allen D. Truell, Ball State University, atruell@bsu.edu \\ Dr. Melody Alexander, Ball State University, malexand@bsu.edu \\ Dr. Jensen J. Zhao, Ball State University, izhao@bsu.edu
}

\begin{abstract}
A focused review of the literature revealed few studies exploring student performance in information systems courses. Thus, this study sought to build upon this limited number of studies and explore the predictive and explanatory power of selected variables on student hands-on performance and theory exam scores in an introductory information systems course. Findings of the study indicate that the variables college GPA, computer liking, and computer systems test score were significant predictor and explanatory variables of student hands-on performance exam scores. By comparison, the variables college GPA, computer systems test score, and perceived computer confidence were found to be significant predictor and explanatory variables of student theory exam scores. Implications for instructional practice are offered.
\end{abstract}

Keywords: Information systems, hands-on performance exam scores, theory exam scores, multiple regression, instructional practice

\section{INTRODUCTION}

A focused review of the literature revealed few studies exploring student performance in information systems courses. This lack of studies is alarming as a number of researchers have reported the critical importance for understanding how selected variables impact student course performance $[1,3,5,7,8,9$, $10]$.

Of the relatively few studies exploring the predictive and explanatory power of selected variables on student performance found in the literature, the Truell and Whitesel [7] and the Truell, Alexander, and Zhao [8] were the most notable. Expressly, Truell and Whitesel [7] found the variable computer systems test score to be a significant predictor and explanatory variable of student performance in an advanced information systems course. More precisely, the variable computer systems test score explained $12.8 \%\left(R^{2}=0.128\right)$ of the variance in final student course performance. In a similar study, Truell et al. [8] found computer liking and gender to

be significant predictor and explanatory variables of final student performance in an introductory information systems course. Expressly, these two variables explained $18.3 \%\left(R^{2}=0.183\right)$ of the variance in final student course performance. A further analysis of the variable gender indicated that female participants achieved significantly higher final performance levels than did male participants. In both the Truell and Whitesel and Truell et al. studies, student performance levels were defined as the final course grade as a percentage. Both Truell and Whitesel [7] and Truell et al. [8] recommended that different aspects of student course performance such as hands-on performance and theory exam scores be explored. Truell and Whitesel [7] and Truell et al. [8] hypothesized that student exam scores might be differ based on its type.

\section{NEED FOR THE STUDY}

Researchers have continuously expressed the need to investigate the variables that impact student course performance $[1,2,3,5,7,8,9,10]$. Most recently, Truell and Whitesel [7] and Truell, et al. [8] have noted the need for studies exploring the predictive and explanatory power of selected variables on student hands-on and theory exam scores. Truell and Whitesel [7] and Truell et al. [8] postulated that the variables impacting student hands-on and theory exams might differ. Thus, this study builds upon and expands the earlier work of other researchers by examining the impact of selected variables on student hands-on performance and theory exam scores.

\section{PURPOSE}

The purpose of this study was to fill a documented need and examine the predictive and explanatory power of selected variables on student hands-on performance and theory exam scores in an introductory information systems course. The selected variables examined in this study included college GPA, computer anxiety, computer applications test score, computer systems test score, 
computer liking, gender, perceived computer competence, perceived quality of prior computer instruction, and weekly computer use (hours). Theses variables were included in this study because they had been explored in similar studies $[1,2,3,5$, $7,8,9,10]$. Expressly, answers to the following research questions were investigated.

1. Do selected variables significantly predict and explain student hands-on performance exam scores in an introductory information systems course?

2. Do selected variables significantly predict and explain student theory exam scores in an introductory information systems course?

\section{RESEARCH METHODOLOGY}

\section{Participants}

One hundred six students enrolled in three intact sections of an introductory information systems course at midsized, Midwestern university served as study participants. This introductory information systems class is the entry course in both the information systems major at the university where the study was conducted. As provided by Institutional Review Board approved protocol, student participation in the study was voluntary. Students who participated in the study were provided with a small incentive.

\section{Instruments}

A number of instruments were used to collect participating student data. Student computer anxiety was established through responses to the Computer Anxiety Index (CAIN). The CAIN consists of 26 items. These 26-items are arranged on 6-point, Likert-type scale with response options ranging from $1=$ strongly agree to $6=$ strongly disagree. Total scores possible for the CAIN range from 26 to 156 , low and high computer anxiety, respectively [6]. Student computer applications and computer systems scores were determined by their responses to parts one and two of the Standardized Test of Computer Literacy. The 29-item computer applications test and the 28-item computer systems test were used in this study. All response options for both tests were multiple choice. These two tests can be used to identify skills possessed by both individuals or groups and to assist program planners in the evaluation of various computer learning experiences [6]. Student perceived computer competence was determined by responses to a 5-point, Likert-type scale which ranged from very low computer competence $=1$ to very high computer competence $=$ 5. Student perceived quality of prior computer instruction was determined by responses to a 5-point, Likert-type scale which ranged from very low quality of instruction $=1$ to very high quality of instruction = 5. Student computer liking was determined by responses to a 5-point, Likert-type scale which ranged from dislike computers very much $=1$ to like computers very much $=5$. Student information regarding average hours of weekly computer use, college GPA, and gender were collected using an information form.

\section{Data Collection Procedures}

Data were collected over two class sessions during the spring 2007 semester. During class session one students were asked to complete the CAIN and the information form; during the second class session two students were asked to complete the computer applications and computer systems tests. Throughout the remainder of the semester, students completed four hands-on performance and four theory exams as part of normal course learning assessments. The results of these four hands-on performance and four theory exams were used to create composite scores for later use in the data analysis.

\section{Data Analysis}

Means and standard deviations were used to describe participant characteristics. Since the purpose of this study was to predict and explain two dependent variables - hands-on performance and theory exam scores, a single multivariate regression analysis was run first. Since the results of the multivariate regression analysis noted several significant variables, the usually univariate regressions were run, one for each of the two dependent variables - handson performance and theory exam scores. The dependent variable hands-on performance score for each student was determined by summing the number of correct responses for each of four exams to create a composite score for that variable; the dependent variable theory exam score for each student was determined by summing the number of correct responses for each of the four to create a composite score for that variable. Multicollinearity of the independent variables was assessed using the procedure outlined by Hair, Anderson, Tatham, and Black [3]. Results of this assessment indicate the use of the variables in the analysis was acceptable. 


\section{RESULTS}

Participating student characteristics and the results of the research questions provide the framework for presenting the results.

\section{Participating Student Characteristics}

Of the 106 students participating in this study, 58 $(54.7 \%)$ were female and $48(45.3 \%)$ were male. The mean level of computer anxiety was reported to be $51.01(\mathrm{SD}=20.09)$. The mean computer applications test score was $10.28(\mathrm{SD}=3.25)$. The mean level of computer liking was $4.26(\mathrm{SD}=0.71)$. The mean computer systems test score was $11.05(\mathrm{SD}=3.08)$. The mean level of perceived prior computer instruction was $3.30(\mathrm{SD}=0.76)$. The mean level of weekly computer use (hours) was 18.39 ( $\mathrm{SD}=$ 10.72). Participant composite hands-on performance and theory exam scores were $114.16(\mathrm{SD}=11.83)$ and $53.79(\mathrm{SD}=6.55)$, respectively. Participant college GPA was $2.75(\mathrm{SD}=0.67)$ on a 4.0 scale.

\section{Research Question One}

Research question one sought to determine the predictive and explanatory power of selected variables for student hands-on performance exam scores in an introductory information systems course. Results of the regression analysis revealed that the variables college GPA, computer liking, and computer systems test score were significant predictor and explanatory variables of student handson performance exam scores in an introductory information systems course. Specifically, the $R^{2}=$ .425 for these two variables accounting for $42.5 \%$ the variance. An $R^{2}=.425$ represents a large effect size [4]. A review of the beta values indicates that the relationship between the dependent and each significant independent variable is positive. The results of this analysis are presented in Table 1.

Table 1

Regression for Predicting and Explaining Student Hands-On Exam Scores $(\mathrm{N}=106)$

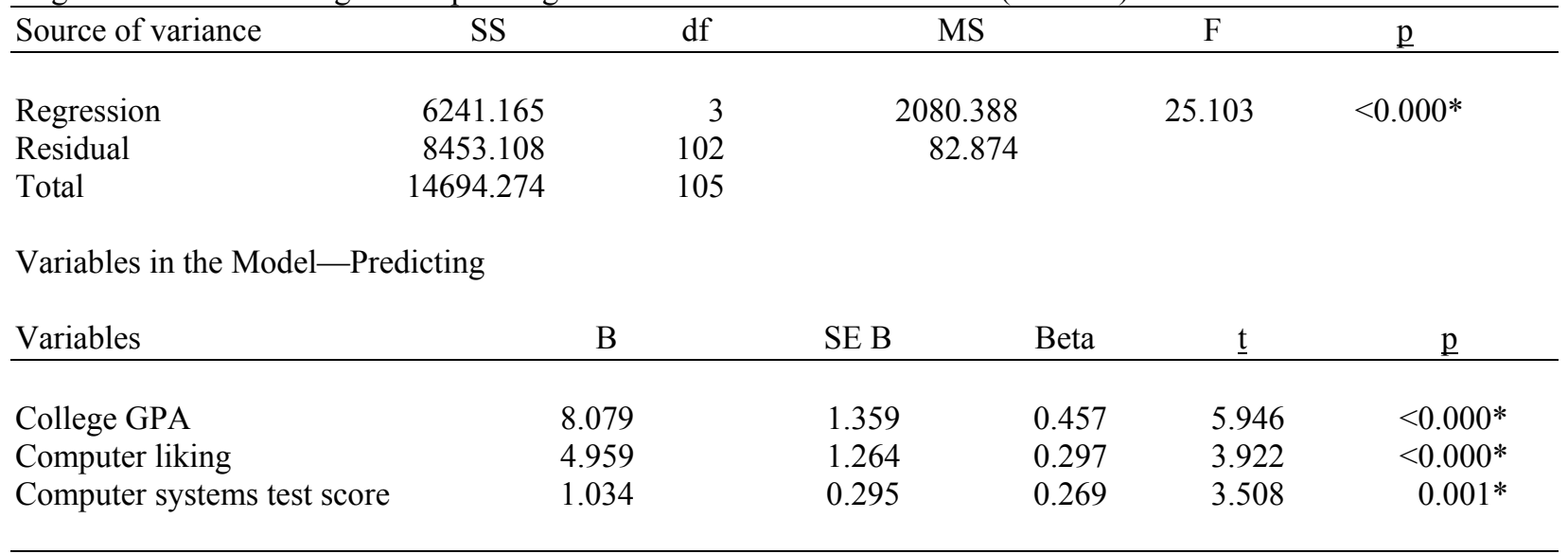

Variables in the Model-Explaining

\begin{tabular}{lcccc} 
Variables & $R^{2}$ & Cum. $R^{2}$ & F-Change & $\underline{p}$ \\
\hline College GPA & & & & \\
Computer liking & 0.282 & 0.282 & 40.782 & $<0.000^{*}$ \\
Computer systems test score & 0.073 & 0.355 & 11.766 & $<0.000^{*}$ \\
& 0.070 & 0.425 & 12.307 & $0.001^{*}$
\end{tabular}

Note. *Significant at $\alpha=.05$.

Research Question Two

Research question two sought to determine the predictive and explanatory power of selected variables on student theory exam scores in an introductory information systems course. Results of the regression analysis revealed that the variables college GPA, computer systems test score, and perceived computer competence were significant predictor and explanatory variables of student theory 
exam scores in an introductory information systems course. Specifically, the $R^{2}=.356$ for these three variables accounting for $35.6 \%$ the variance. An $R^{2}=$ .356 represents a large effect size [4]. A review of the beta values indicates that the relationship between the dependent and each significant independent variable is positive. The results of this analysis are presented in
Table

Table 2

Regression for Predicting and Explaining Student Theory Exam Scores $(\mathrm{N}=106)$

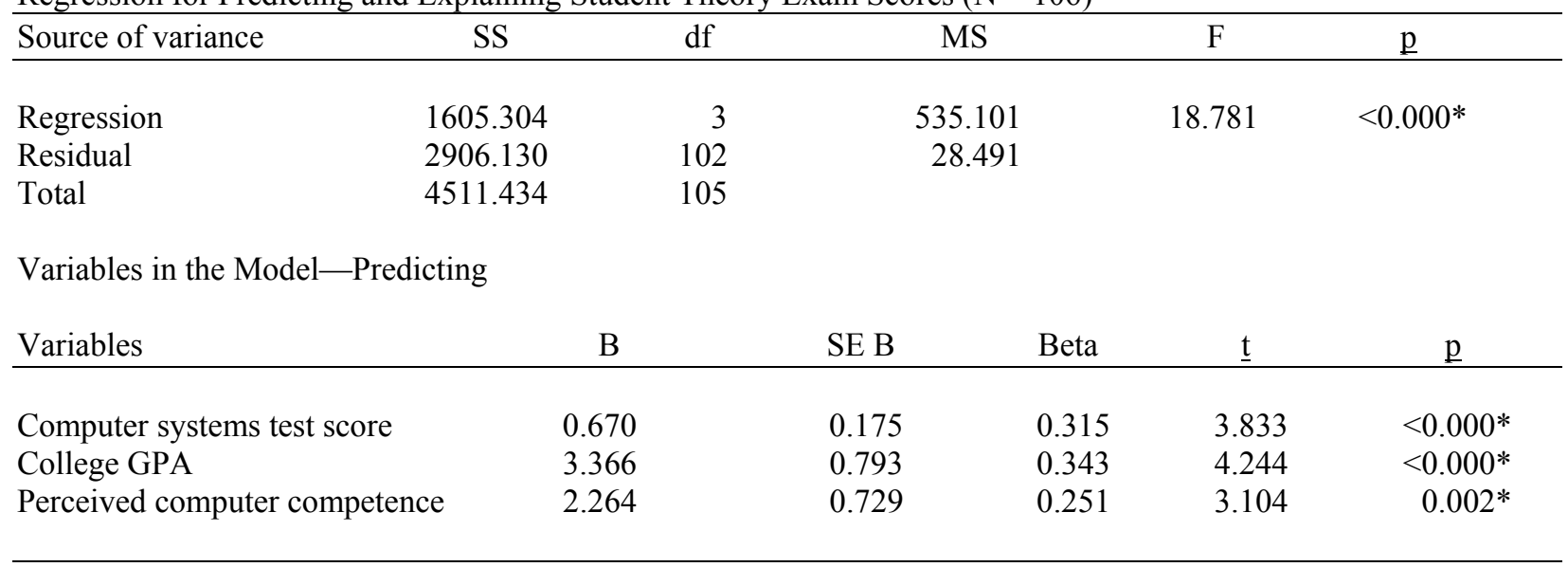

Variables in the Model—Explaining

\begin{tabular}{lcccc} 
Variables & $R^{2}$ & Cum. $R^{2}$ & F-Change & $\underline{p}$ \\
\hline Computer systems test score & & & & \\
College GPA & 0.180 & 0.180 & 22.851 & $<0.000^{*}$ \\
Perceived computer competence & 0.115 & 0.295 & 16.775 & $<0.000^{*}$ \\
& 0.061 & 0.356 & 9.637 & $0.002^{*}$
\end{tabular}

Note. ${ }^{*}$ Significant at $\alpha=.05$.

\section{CONCLUSIONS AND IMPLICATIONS}

One hundred six students at one midsized, Midwestern university enrolled in three intact sections of an introductory information systems course participated in the study. Thus, generalization beyond the results of this participant group is limited. The following conclusions are put forward with that concern noted. As supported by data in Tables 1 and 2 , selected variables are significant predictor and explanatory variables of student hands-on performance and theory exam scores in an introductory information systems course. These variables, however, were not the same for each exam type, hands-on performance or theory. The variables college GPA and computer systems test score were significant predictor and explanatory variables of both student hands-on performance and theory exam scores in this study. The variable computer liking was found to be an additional predictor and explanatory variable of student hands-on performance exam scores in this study. The variable perceived computer competence was found to be an additional predictor and explanatory variable of student theory exam scores in this study.

The results of this study offer several implications for practice. The better students did on the computer systems test, the more they liked computers, and the higher their perceived computer competence, the better they tended to do on their hands-on performance and/or theory exams. These results suggests that introductory information systems instructors might consider administering a content specific literacy test to students at the beginning of the class. Such a content specific literacy tests would provide instructors with insight into preexisting student knowledge which should assist with planning the teaching/learning process. Additionally, an assessment of student computer liking and perceived computer competence might provide introductory information systems course instructors with 
additional insight into likely student performance levels on various class assessment. With this additional insight, introductory information systems course instructors can adapt instructional strategies that best fit their students.

\section{RESEARCH RECOMMENDATIONS}

Based on the review of the literature and findings of this study, the following recommendations for future research are put forward:

1. Since this appears to be the first study to examine the predictor and explanatory variables impacting student scores on both hands-on performance and theory exam scores, it should be replicated. Future replications of this study would provide additional insight into the predicator and explanatory variables of student hands-on performance and theory exam scores.

2. Since this study examined student hands-on performance and theory exam results as composite scores, it is recommended that studies be conducted to assess the predictor and explanatory power of selected variables on each of these individual exams. Such studies would provide additional insight into the predicator and explanatory variables of student hands-on performance and theory exam result for each assessment completed.

\section{REFERENCES}

1. Cooper, L. (2001). A comparison of online and traditional computer applications classes. T.H.E. Journal, 28(8), 53 - 54, 56, 58.

2. Erthal, M. J. (1998). Analysis of performance in a microcomputer applications class. The Delta Pi Epsilon Journal, 40(1), 36 - 49.
3. Hair, J. F., Anderson, R. E., Tatham, R. L., \& Black, W. C. (1998). Multivariate data analysis (5th ed.). Upper Saddle River, NJ: Prentice Hall.

4. Kotrlik, J. W., \& Williams, H. A. (2003). The incorporation of effect size in information technology, learning, and performance research. Information Technology, Learning, and Performance Journal, 21(1), 1 - 7.

5. Ross, J. L., Drysdale, M. T. B., \& Schulz, R. A. (2001). Cognitive learning styles and academic performance in two postsecondary computer application courses. Journal of Research on Computing in Education, 33(4), 400 - 412.

6. Simonson, M. R., Montag, M., Maurer, M., Oviatt, L., \& Whitaker, M. (1992). Test administrator's manual for the Standardized Test of Computer Literacy and Computer Anxiety Index. Iowa State University Press.

7. Truell, A. D., \& Whitesel, J. A. (2004). Final student performance in an advanced university computer applications course: Implications for curriculum planning. Journal of Business and Training Education, 13, 103 - 115.

8. Truell, A. D., Alexander, M. W., \& Zhao, J. J. (2005). Predicting and explaining student introductory computer applications final course performance. The Ohio Business Technology Educator, $L X V, 39-49$.

9. Weston, T. L., \& Baker, L. J. (2002). A profile of student computer use, training, and proficiency. Journal of Computing in Higher Education, 14(1), $87-112$.

10. Wiggs, L. H., Huter, L., \& Erthal, M. (1998). Microcomputer applications: A unique challenge for educators. Office Systems Research Journal, 16(1), 15 - 20. 